\title{
Electrical Performance and Effect of Frequency Electromagnetic Waves on Subterranean Termites Coptotermes curvignathus Holmgren
}

\author{
Seno D. Panjaitan ${ }^{1}$, Farah Diba ${ }^{2}$, Ferry Hadary ${ }^{1}$, Tsuyoshi Yoshimura ${ }^{3}$ \\ ${ }^{1}$ Department of Electrical Engineering, Faculty of Engineering, Tanjungpura University, Pontianak, Indonesia; ${ }^{2}$ Department of \\ Forestry, Faculty of Forestry, Tanjungpura University, Pontianak, Indonesia; ${ }^{3}$ Research Institute for Sustainable Humanosphere, \\ Kyoto University, Kyoto, Japan. \\ Email: senopanjaitan@gmail.com
}

Received October $29^{\text {th }}, 2013$; revised November $26^{\text {th }}, 2013$; accepted December $21^{\text {st }}, 2013$

Copyright (C) 2014 Seno D. Panjaitan et al. This is an open access article distributed under the Creative Commons Attribution License, which permits unrestricted use, distribution, and reproduction in any medium, provided the original work is properly cited. In accordance of the Creative Commons Attribution License all Copyrights (C) 2014 are reserved for SCIRP and the owner of the intellectual property Seno D. Panjaitan et al. All Copyright (C) 2014 are guarded by law and by SCIRP as a guardian.

\section{ABSTRACT}

The research aimed to propose a non-destructive technology to control subterranean termites Coptotermes curvignathus Holmgren infestation based on electromagnetic waves. A portable apparatus for this technology has been built and its experiment is presented in this paper. Some electrical parameters were measured and analyzed along with their effects to the termites. The experiment using frequency range between $30 \mathrm{~Hz}-600 \mathrm{kHz}$ has been done. The average error of the apparatus by comparing the result with the direct measurement using oscilloscope was also measured. The highest error value appeared at $600 \mathrm{kHz}$ with frequency error $6.05 \mathrm{kHz}$. The highest error of voltage (i.e. 0.186 Volt) appeared at $100 \mathrm{kHz}$. For safetiness, the highest magnetic field at 300 $\mathrm{kHz}$ was $0.1815 \mu \mathrm{T}$ and at $500 \mathrm{kHz}$ was $0.00725 \mu \mathrm{T}$ which were safe for human. The average value of termites mortality was higher on irradiation time 120 minutes than 60 minutes respectively in all test frequency: $300 \mathrm{kHz}$, $400 \mathrm{kHz}, 500 \mathrm{kHz}$ and $600 \mathrm{kHz}$. This paper presents an important information of the electromagnatic-based technology for environmental friendly termites control in spite of using the insecticides.

\section{KEYWORDS}

\section{Electromagnetic Waves; Frequency; Subterranean Termites; Coptotermes curvignathus; Termites Infestation}

\section{Introduction}

Nowadays, termites are known as a group of serious pests in the world. They often cause serious damage to wooden furnitures and buildings. The damage caused by termites has an important economic effect. In Indonesia, the damage costs could reach to 100 - 300 billion rupiahs every year [1]. One of the important groups of urban insect pests in tropical countries is subterranean termites Coptotermes curvignathus Holmgren [2]. Termites are insects which are successfully to adapt in various condition of settlements and farms. Their ability to survive in settlements area is also influenced by their life style which is colonized in big numbers [3]. The chemical treatments, including soil treatment, wood impregnation, or fumigation have been widely used over the last few decades. However, an increased public concern about unfavorable effects would not support the massive use of insecticides any more [4]. Concisely, the use of chemical teratments may bring a destructive effect to the environment.

A new solution to control the termites is urgently needed which is an attractive research issue. The on-site termite treatment with physical methods is one of the most promising alternatives. One of the technologies which are potential to be developed is the use of electromagnetic waves technology. Electromagnetic wave or electromagnetic radiation is a combination of electric and magnetic fields that oscillate and propagate through space and carry energy from one place to another [5]. In the present day, the use of electromagnetic waves has 
also been considered in efforts to eliminate termites. Some patents related to the use of electromagnetic technology such as US Patent No. 5,473,836 issued to Liu [6], which disclosed a method for removing insects from hidden place by inducing an electromagnetic field to create physical vibrations. Another US Patent No 5,442,876 issued to Pederson [7] disclosed a method for controlling termites by heating the area where termites were located by means of electromagnetic energy. This technology is odorless, noiseless, environment friendly and easy to apply. However, there is no detail research conducted on the response of about subterranean termites Coptotermes curvignathus against electromagnetic waves.

This paper presents the research development on the use of electromagnetic waves to repel or to eliminate the subterranean termite Coptotermes curvignathus by means of changing their common behaviour. The main objective of this study is to build and test an apparatus developed to produce variable electromagnetic waves to influence the behavior of termites and to prevent their infestation in buildings.

\section{Materials and Method}

The research was carried out in Tanjungpura University Pontianak (Indonesia) and Research Institute for Sustainable Humanosphere (RISH) Kyoto University (Japan). The primary circuit built for the apparatus were as follows: voltage control, frequency control, amplifier, microcontroller circuit, rectifier, Liquid Crystal Display (LCD) circuit, and electromagnetic transmitter. The apparatus was covered by an acrylic package. Some materials used for the experiment were termites Coptotermes curvignathus, wood dust, sand and distilled water as substrate for termites breeding, Whatman filter paper, distilled water, petridish, and analytic balance. Furthermore, several measurement equipments used were electromagnetic field (EMF) tester (Hioki 3470-10, Japan), function generator and oscilloscope.

The procedure of this research consisted of two main parts: 1) apparatus development, testing and electrical performance analysis and 2) bioassays. The development of a compact temites control apparatus (TCA) (cf. Figure 1) involved several functionalities such as power supply, voltage and frequency control, voltage and frequency display, electromagnetic generation. The analysis of electrical parameters performance was dealt with frequency, voltage, waveform and electromagnetic field. The electric power output $(\mathrm{P})$ was measured by power meter and power density was calculated as follow:

$$
D \approx \frac{P}{\frac{\lambda}{4} \times \frac{\lambda}{2}}\left(\mathrm{~mW} / \mathrm{cm}^{2}\right)
$$
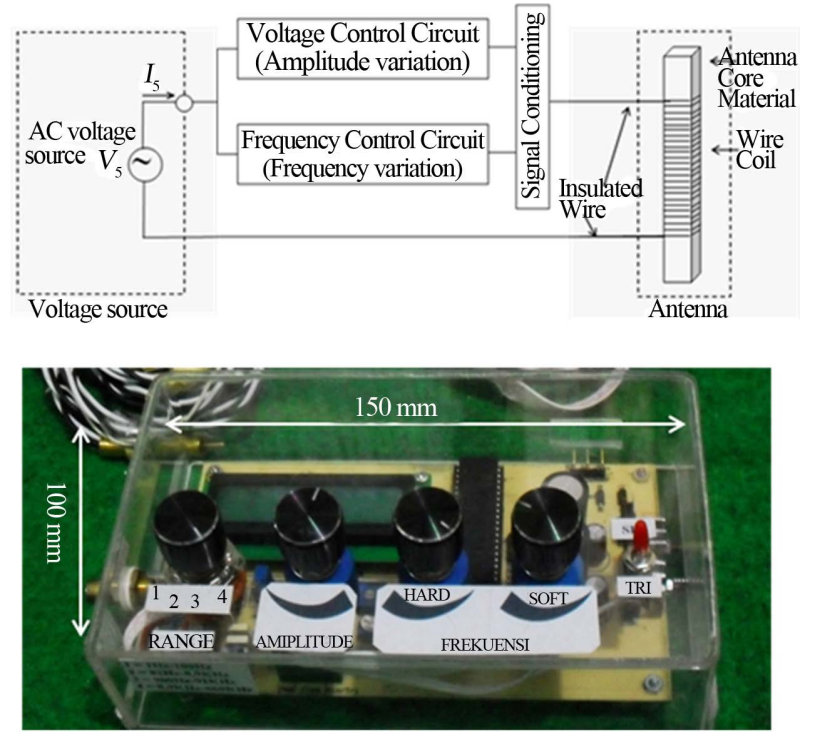

Figure 1. The Developed Termites Control Apparatus.

The design and building the apparatus was done in Control Systems Laboratory, Engineering Faculty, Tanjungpura University, Indonesia. The design was based on some references [8-10]. The proposed concept mainly adopted the previous concept of the authors [11] by developing frequency range, compatibility and electromagnetic field range. In our previous research [11], the optimal frequency to repel the termites was about 300 $\mathrm{kHz}$ with a limitation on the electromagnetic field radius $(5-10 \mathrm{~cm})$, limit of voltage in the higher frequency (about 2 Volt in frequency about $300 \mathrm{kHz}$ ) and its incompatibility (frequency and voltage setting had to use the oscilloscope).

The development of it presented in this paper increase the frequency range and compatibility faced at the beginning of the development. The built apparatus provides a frequency range between $0-600 \mathrm{kHz}$, voltage range 0 16 Volt, and a compatibility product (frequency and voltage setting could be perfomed directly at the apparatus). By the providing frequency and voltage set panel in the apparatus, the user will be easily use and set the required frequency and voltage which is determined by the research results. This is one step to the commercial product.

Furthermore, the subterranean termite $C$. curvignathus colony was taken from Arboretum Forestry Faculty, Tanjungpura University and maintained in the Wood Laboratory of Forestry Faculty at $25^{\circ} \mathrm{C}$ and $75 \%$ RH. For testing the TCA, a construction model of a residential building-like test-bed shown in Figure 2 was built. Scale of the model was $500 \mathrm{~mm}$ width, $1000 \mathrm{~mm}$ length and $250 \mathrm{~mm}$ height. It was built by using transparent acrylic material for the walls and several wood made furniture inside of the house. 


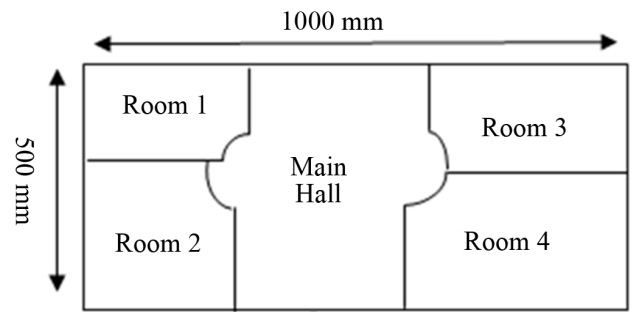

Figure 2. A Residential Building-like Test-bed.

Bioassays with the TCA to termites in the test-bed were perfomed afterwards. Effect of the electromagnetic fields was analyzed by putting the TCA on the top of the room 4 of residential building test bed. The container which measure $5 \mathrm{~mm}$ height and $120 \mathrm{~mm}$ diameter then put inside the room 4. Mature workers and soldiers of $C$. curvignathus then put into container which contain filter paper as a food for termites. The numbers of termites used were 100 soldiers and 1000 workers. This number was selected to obtain a nearly equal weight/volume of termites for electromagnetic waves irradiation. The frequencies of TCA used were $300 \mathrm{kHz} ; 400 \mathrm{kHz} ; 500 \mathrm{kHz}$ and $600 \mathrm{kHz}$ respectively. Time exposure of TCA to termites was 60 minutes and 120 minutes. Termites behavior during bioassay was observed. After irradiation of electromagnetic waves, termites were removed to petridish to evaluate the termites mortality. Petridish with diameter $120 \mathrm{~mm}$ contained filter paper (Whatman No 2) which saturated with $0.4 \mathrm{ml}$ distilled water. Termites were kept for 24 hour in a termite culturing room, and then afterwards the mortality of termites was count. Termite mortality was calculated based on Nakai et al. [12] as follows:

$$
\text { Termites Mortality }(\%)=\frac{N_{2}}{N_{1}} \times 100 \%
$$

$N_{1}=$ Number of initial termites

$N_{2}=$ Number of death termites after 24 hour exposure

Evaluation of the safetiness of electromagnetic effect for human and non-target organisms was further analyzed by using Electro Magnetic Field (EMF) tester (Hioki 3470-10, Japan). The measurement was performed by putting TCA in several positions regarding the $\mathrm{x}-\mathrm{y}-\mathrm{z}$ axis of the EMF tester according to Thide Bo [13]. The result was compared to home electronic equipments magnetic field listed by Kato [14]. Thus, the safetiness of the TCA was concluded.

\section{Results and Discussion}

\subsection{Electrical Performance}

The electrical parameters performance was measured by classifying into several group of frequency, i.e. $30 \mathrm{~Hz}$, $150 \mathrm{~Hz}, 300 \mathrm{~Hz}, 1 \mathrm{kHz}, 2 \mathrm{kHz}, 3 \mathrm{kHz}, 10 \mathrm{kHz}, 15 \mathrm{kHz}$, $30 \mathrm{kHz}, 40 \mathrm{kHz}$, and $50 \mathrm{kHz}$ respectively. Figure 3 shows the electrical parameters regarding set frequencies which are shown on LCD display of apparatus and the maximum voltage that can be set.

The maximum voltage set in the TCA was 20 Volt, while in the higher frequency it tended non-linearly to operate with lower frequency. This is caused by the requirement of current (necessity for more power to operate the TCA) for some frequency groups become higher than the lower frequency groups. To improve the voltage value of the TCA, the amplification could be done along with the power of it.

Furthermore, the average of rising time in accordance with the set frequency depicted in Figure 4. This data is used for explain the stability of electromagnetic waves for some period of time by the influence of the used frequency. The results shows how fast the real voltage could reach the set voltage. The lower frequency resulted the higher rising time, although it is not linier as shown in Figure 4. This means that TCA electromagnetic in lower frequency the steady-state could reach faster start from $2000 \mathrm{~Hz}$. Therefore we continued the bioassay of termites to know the influence of TCA to control termite start on $3000 \mathrm{~Hz}$.

In order to examine the precision of frequency and voltage that are set at the TCA, their values were compared to direct measurement using standardized oscilloscope. There were small errors in some set frequency. Table 1 lists the average error in frequency between 30 $\mathrm{Hz}-600 \mathrm{kHz}$. The highest error of frequency was appear at $600 \mathrm{kHz}$ (i.e. $6,05 \mathrm{kHz}$ ) and of voltage at $100 \mathrm{kHz}$ (i.e. 0.186 Volt). Since the selected frequency was purposed not to apply in the communication field, the approximation could be done hence the percentage of the average error is still acceptable.

Figures 5 and 6 show the waveform and electrical parameters for frequency $300 \mathrm{kHz}$ and $500 \mathrm{kHz}$. There is no harmonic distortion at both frequencies. The waveform and electrical parameteres was taken to be compare to the frequency and voltage shown in the LCD circuit of the apparatus.

In the set frequency $300 \mathrm{kHz}$, there is a small error of frequency, where the real frequency is $301.2 \mathrm{kHz}$ and the error is $1.2 \mathrm{kHz}$. Since the purpose of the apparatus was not for communication, the small error presented in the apparatus had no problem. The important thing in this application is that the effect of electromagnetic waves with the set frequency that can affect to the termites infestation. Our previous research showed that the set frequency of $300 \mathrm{kHz}$ brings the optimal effect to influence the mortality of termites [15]. The rising time either for set frequency $300 \mathrm{kHz}$ is 1.120 ps (for Vpp 4 


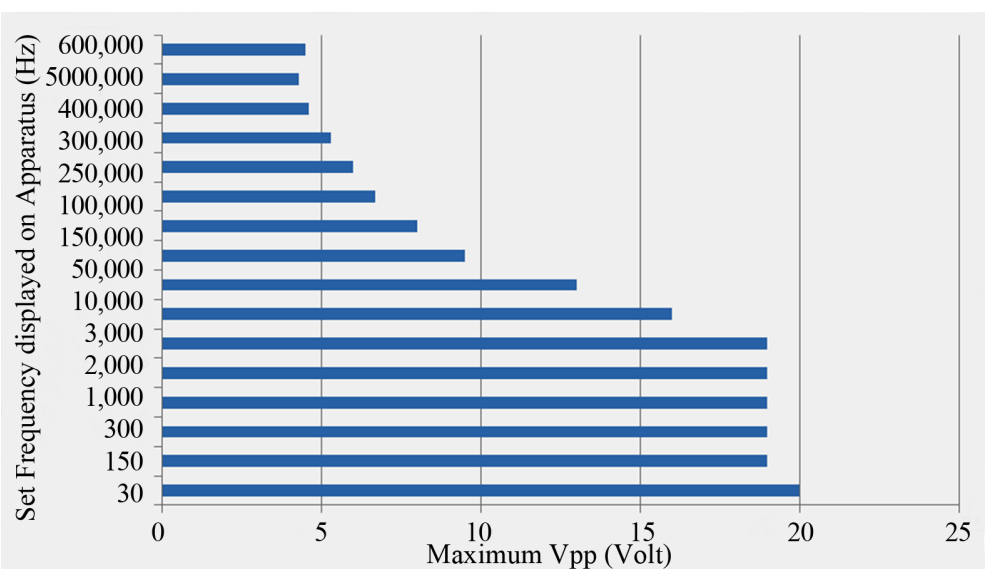

Figure 3. Maximum of Vpp against set frequency.

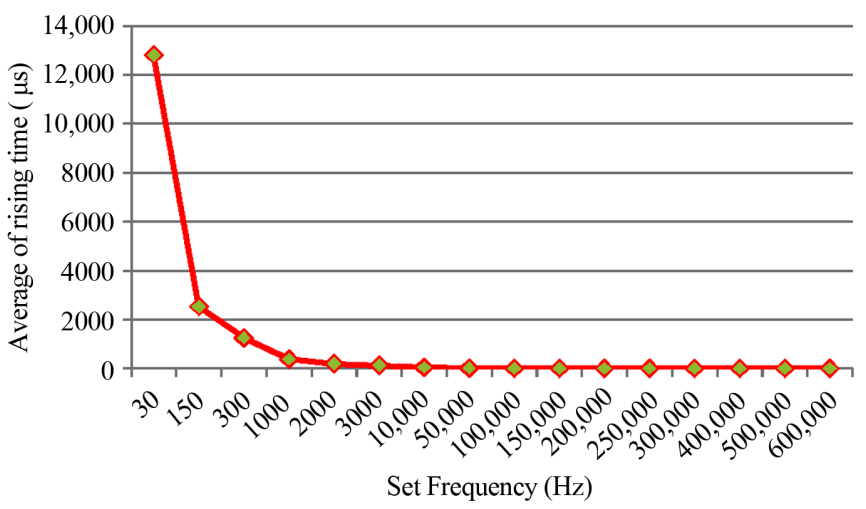

Figure 4. Average of rising time against set frequency.

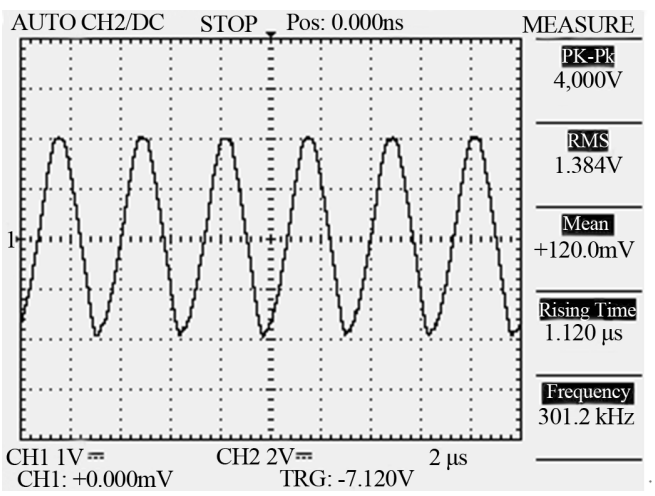

(a)

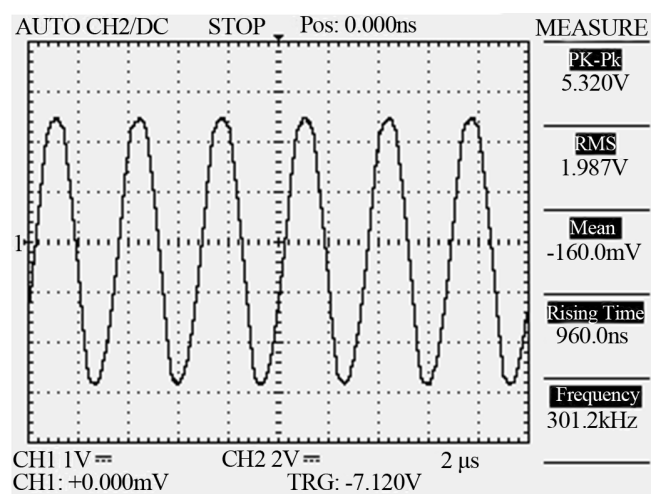

(b)

Figure 5. Waveform and electrical parameters of the TCA on frequency $300 \mathrm{kHz}$. (a) $4 \mathrm{Vpp}$, (b) $5.3 \mathrm{Vpp}$.

Volt) and $0.960 \mu$ s (for Vpp 5.32 Volt). While for the set frequency $500 \mathrm{kHz}$, the rising time is about $650 \mathrm{~ns}$. Rising time represents the time needed to reach the set voltage. The faster rising time means the faster set voltage reached.

\subsection{Electromagnetic Influence to the Termites}

The frequencies of TCA used were $300 \mathrm{KHz} ; 400 \mathrm{KHz}$;
$500 \mathrm{KHz}$ and $600 \mathrm{KHz}$ respectively. Time exposure of TCA to termites was 60 minutes and 120 minutes. Termites were put in room 4 and after 10 (ten) minute's exposure, the termites was move to other room of residential building-like test-bed. This can be indicated that termites disturbed by electromagnetic waves. This event occurs for all frequencies of TCA. Similar result was achieved on Kevin et al. research [16]. 


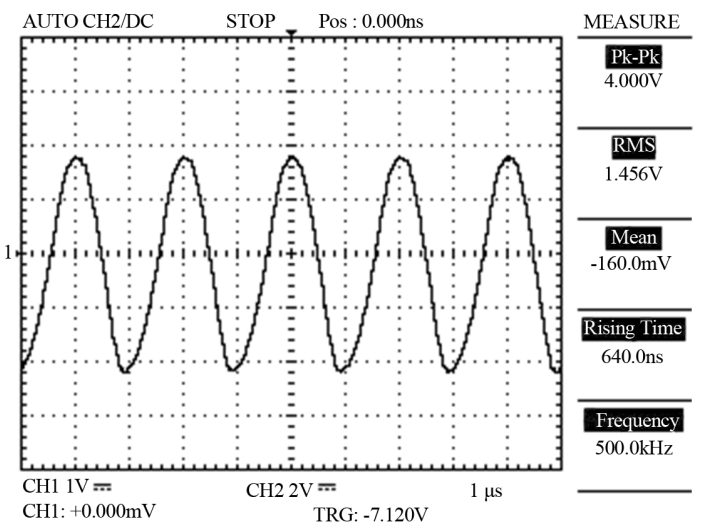

(a)

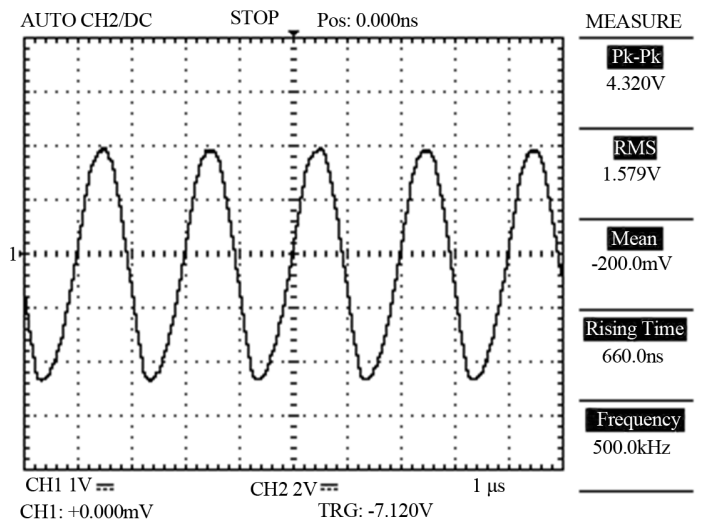

(b)

Figure 6. Waveform and electrical parameters of the TCA on frequency $500 \mathrm{kHz}$. (a) $4 \mathrm{Vpp}$, (b) $4.3 \mathrm{Vpp}$.

Table 1. Average error of frequency and voltage.

\begin{tabular}{ccc}
\hline \multirow{2}{*}{$\begin{array}{c}\text { Set Frequency } \\
(\mathrm{Hz})\end{array}$} & Average Error $=$ set value - measured value \\
\cline { 2 - 3 } 30 & 0.12 & Vpp $($ Volt $)$ \\
150 & 0.66 & 0.056 \\
300 & 1.2 & 0 \\
1000 & 0 & 0.016 \\
2000 & 0 & 0.016 \\
3000 & 15.6 & 0.072 \\
10,000 & 0 & 0.04 \\
50,000 & 0 & 0.026 \\
100,000 & 0 & 0.32 \\
150,000 & 1150 & 0.186 \\
200,000 & 800 & 0.04 \\
250,000 & 0 & 0.03 \\
300,000 & 1200 & 0.04 \\
400,000 & 3200 & 0.01 \\
500,000 & 0 & 0.04 \\
600,000 & 6050 & 0.01 \\
\hline
\end{tabular}

During exposure of electromagnetic waves, termites were tended to move away from the container. When the frequency electromagnetic waves was $300 \mathrm{kHz}$ the termites moves from room 4 to other room, i.e. room 3, room 2 and main hall. After 60 minutes exposure there are some worker of termites loss of stability. When the frequency electromagnetic waves was $400 \mathrm{kHz}$ the termites moves from room 4 to room 3 and main hall. After 60 minutes exposure there are some worker of termites loss of stability and lying. Similar result was achieved when the frequency of electromagnetic $500 \mathrm{kHz}$. The termites move to room 3 and main hall and after $60 \mathrm{mi}-$ nutes we found some termites worker lying. When the frequency of electromagnetic waves was $600 \mathrm{kHz}$ the termites look disturbed, they loss of stability, shaking and some termites moves from room 4 to main hall only. They cannot reach the room 3 and other room. This is because the effect of electromagnetic so strong and on the treatment 120 minutes of exposure time, we found some workers of termites death. This could indicate that electromagnetic fields affected the physiology of termites and acted as a repellent to termites. According to Kevin et al. [16] termites movement was positive directed by radio waves and electromagnetic waves and they could be used as control apparatus for termites.

The average value of termites mortality was higher on frequency $600 \mathrm{KHz}$ than other frequency and higher on exposure time 120 minutes than 60 minutes respectively as shown in Table 2. According to Kraus [17] electromagnetic waves has an effect to nervous system. He has found that there is a complex field pattern which is spatially related to the anatomical arrangement of the nervous system. The time of exposure of electromagnetic waves had a positive effect to the value of termites mortality. The longest time of exposure of electromagnetic waves caused the highest average value of termites mortality. It can be seen that the effect of electromagnetic related to the frequency and time of exposure. The lower time of exposure determined for the application of apparatus means the the lower effect to the termites mortality. This could be indicated that further application of TCA in residential need more than 120 minutes to move the termites colony away. Electromagnetic waves are combination of electric field and magnetic field which frequencies provide the main influence to materials [18]. Ivanovich [19] stated that storage of agri- cultural products in the warehouse that were given lowfrequency electromagnetic waves have a positive impact. 
Table 2. Mortality of termites $C$. curvignathus after irradiation with electromagnetic waves from TCA with different frequency and time of exposure.

\begin{tabular}{ccc}
\hline \multirow{2}{*}{ Frequency } & \multicolumn{2}{c}{ Time Exposure } \\
\cline { 2 - 3 } & 60 minutes & 120 minutes \\
\hline $300 \mathrm{KHz}$ & $9.09^{\mathrm{a}}$ & $13.64^{\mathrm{a}}$ \\
$400 \mathrm{KHz}$ & $11.36^{\mathrm{a}}$ & $17.27^{\mathrm{b}}$ \\
$500 \mathrm{KHz}$ & $20.45^{\mathrm{b}}$ & $26.18^{\mathrm{c}}$ \\
$600 \mathrm{KHz}$ & $27.91^{\mathrm{c}}$ & $37.73^{\mathrm{d}}$ \\
\hline
\end{tabular}

${ }^{\mathrm{a}}$ Means $(n=5) \pm$ SD. Numbers followed by different letters (a-d) are significantly different at the level of $P<0.05$ according to Tukey's test.

Agricultural products are of good quality. Thus the frequency has a significant impact on the use of electromagnetic waves.

The frequency must be determined to be applied for a special purpose. Furthermore, the effect of frequency to produce electromagnetic waves give more effect to the termites mortality then the safetiness of TCA need to be evaluated. Other research by Nakai et al. [12] using microwave energy with two frequencies, $2.45 \mathrm{GHz}$ and 5.8 $\mathrm{GHz}$ to control the drywood termites Incisitermes minor and the subterranean termites Coptotermes formosanus Shiraki. It was reported that the mortality of termites was higher at the higher microwave energy and longest irradiation time. The highest termites mortality value, both on Coptotermes formosanus and Incisitermes minor termites was obtained when termites were exposed to microwave energy on frequency $5.8 \mathrm{GHz}$ than $2.45 \mathrm{GHz}$. Furthermore, previous result of the authors related to this paper also achieved the similar result [15].

\subsection{Safetiness}

The frequency designed for TCA must be checked for their effects on human beings. According to Kato [14] the frequency of electromagnetic waves has a relation with bio-electromagnetic and relatively a new area of science that deals with the interaction of electromagnetic energy with biological systems. The safetiness analysis of the built apparatus was done at Research Institute for Sustainable Humanosphere (RISH), Kyoto University, Japan.

The measurement was carried out respectively on the axis $\mathrm{x}, \mathrm{y}$ and $\mathrm{z}$ (three dimension of field radius) in which the electromagnetic wave propagation data on each axis was done of the difference varies with the distance of 1 $\mathrm{cm}$. Ten replications were done for each position. To measure and evaluated the range of magnetic field we use EMF Hioki 3470-10 (Japan).

Figure 7 shows the average value of magnetic field

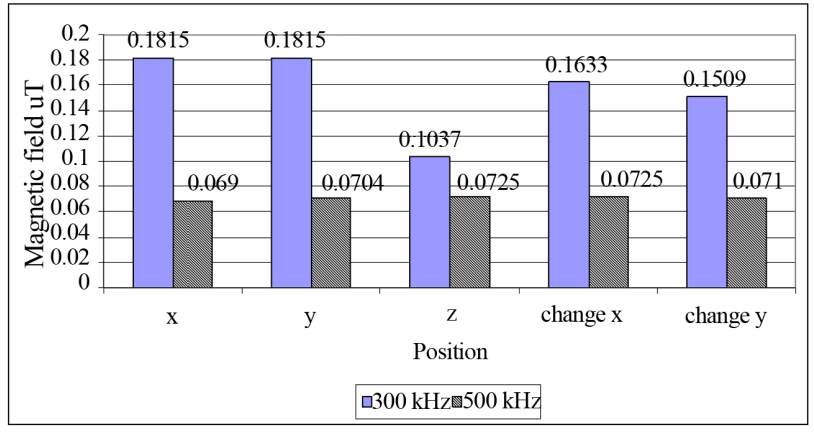

Figure 7. Magnetic field from TCA with frequencies 300 kHz and $500 \mathrm{kHz}$.

from electromagnetic waves apparatus for the frequency range at $300 \mathrm{kHz}$ and $500 \mathrm{kHz}$ in terms of $x-y-z$ axis. The measurement was purposed to investigate its impact to the human. The electromagnetic field can also be found on many electronic appliances such as hair dryers $(0.1$ $70 \mu \mathrm{T})$, coffee makers $(0.4-1 \mu \mathrm{T})$, mixers $(3-60 \mu \mathrm{T})$, washing machines $(0.4-10 \mu \mathrm{T})$, fax machines $(0.4-0.9$ $\mu \mathrm{T})$ and so forth. From the few examples of magnetic field data in some electronic equipment that is used daily in the household, it was proven that the electromagnetic waves apparatus used in the present study was safe to use and did not have an influence on human beings.

The measurement results of magnetic fields for frequency $500 \mathrm{KHz}$ was obtained that on the $\mathrm{x}$ axis was $0.0690 \mu \mathrm{T}$, at the axis y was $0.0704 \mu \mathrm{T}$ and, $0.0725 \mu \mathrm{T}$ on $\mathrm{z}$ axis. Meanwhile, if the measurement was done at the middle coil, then the results of measurement for $\mathrm{x}$ axis was $0.0725 \mu \mathrm{T}$ and for the y-axis was $0.071 \mu \mathrm{T}$. Refering to the data from the National Research Council, USA 1997 [20], it clearly shows that the use of this TCA apparatus at a frequency of $500 \mathrm{KHz}$ has no impact to the biology metabolism of human beings.

\section{Conclusion}

The present study has elucidated that the TCA electromagnetic-based technology has potential to be applied to control termites infestation by influencing their infestation. A compact apparatus has been built and tested. The optimal frequency for this apparatus to control the termites was $600 \mathrm{kHz}$. Furthermore, some little errors were still found in some frequencies in terms of frequency and voltage of apparatus compared to the measurement using oscilloscope. However, this error was still in the tolerance since the application was not for communication. In term of time of exposure, it is better to use more than 120 minutes. For safetiness, the apparatus is safe for application arround human beings since the magnetic fields produced is still in tolerance. This paper presents an important information for non-destructive and environ- 
mental friendly termites control technology in spite of using the insecticides.

\section{Acknowledgements}

The authors would gratefully like to thank Ministry of Education and Culture Indonesia for funding this research in program scheme Collaborative Research and International Publication Grant in 2012-2013. The authors appreciate and thank to Dr. Tomohiko Mitani for a valuable discussion and his help providing the EMF tester for safety analysis, also we would like to thank the technical support provided by Merry Sensiana and Andika.

\section{REFERENCES}

[1] D. Nandika, Y. Rismayadi and F. Diba, "Termites: Biology and Its Control,” Muhammadiyah University Press, Surakarta, 2003.

[2] C. Y. Lee, C. Vongkaluang and M. Lenz, "Challenges to Subterranean Termite Management of Multi-Genera Faunas in Southeast Asia and Australia," Sociobiology, Vol. 50, No. 50, 2007, pp. 213-221.

[3] A. Brune, “Termites: Woodworker's Digest,” Nature, Vol. 11, No. 450, 2007, pp. 61-67.

[4] K. Tsunoda, "Improved Management of Termites to Protect Japanese Homes," Proceedings of the 5th International Conference on Urban Pests, Singapore, 10-13 July 2005, 33-37.

[5] Supriyanto, "Electromagnetic Waves Propagation," Indonesia University Press, Jakarta, 2007.

[6] M. Liu, US Patent No. 5473836, 2007.

[7] Ib O. Pederson, US Patent No 5442876, 2007.

[8] M. F. Kabir, T. D. Leininger, P. A. Araman and M. F. Winn "Detection of Wetwood by Ultrasonics," Forest Product Journal, Vol. 56, No. 3, 2006, pp. 22-26.

[9] L. G. Lawrence, US Patent No 5210719, 2007.

[10] K. Nakai, T. Mitani, T. Yoshimura, N. Shinohara, K. Tsunoda and Y. Imamura, "Microwave Technology as a NonDestructive Termite Control Method-Preliminary Results," Proceeding 6th Pacific Rim Termites Research Group,
Kyoto, 2009, pp. 36-40.

[11] F. Diba, F. Hadary, S. D. Panjaitan and T. Yoshimura, "Electromagnetic Waves as Non-Destructive Method to Control Subterranean Termites Coptotermes curvignathus Holmgren and Coptotermes formosanus Shiraki," Procedia Environmental Sciencesr, Vol. 17, 2013, pp. 150159.

[12] K. Nakai, T. Mitani, T. Yoshimura, N. Shinohara, K. Tsunoda and Y. Imamura, "Effects of Microwave Irradiation on the Drywood Termites Incisitermes minor Hagen,” Japan Journal Environment Entomology Zoology, Vol. 20 No. 4, 2009, pp. 179-184.

[13] T. Bo, "Electromagnetic Field Theory,” Upsilon Books Inc, Sweden, 2008.

[14] M. Kato, "Electromagnetics in Biology," Springer, Tokyo, 2006. http://dx.doi.org/10.1007/978-4-431-27914-3

[15] F. Diba, F. Hadary, S. D. Panjaitan and T. Yoshimura, "Development Bio-Control Technology for Subterranean Termites Coptotermes curvignathus Holmgren Using Electromagnetic Waves," International Wood Research Journal, Vol. 1, No. 2, 2010, pp. 71-77.

[16] J. Kevin, N. Kartal, B. Derk and K. Wyne, "Positive Directed Movement of Termites by Radio Waves as a Basis for Control Procedures,” Forest Product Journal, Vol. 5, No. 3, 2007, pp. 237-241.

[17] J. D. Kraus, "Electromagnetics,” Mc Graw Hill Inc, New York, 2006.

[18] Y. Ju, Y. Hirosawa, M. Saka and H. Abe,“Development of a Millimeter Wave Compact Equipment for NDT of Materials,"'International Journal of Infrared and Millimeter Waves, Vol. 24, No. 3, 2003, pp. 391-397. http://dx.doi.org/10.1023/A:1021843003475

[19] K. G. Ivanovich, S. I. Evgenyevich, G. A. Vasilyevich, D. T. Nikolaevna and V. E. Igorevich, "Features of Usage of Electromagnetic Field of Extremely Low Frequency for the Storage of Agricultural Products," Journal of Electromagnetic Analysis and Applications, Vol. 5, 2013, pp. 236-241 http://dx.doi.org/10.4236/jemaa.2013.55038

[20] G. R. Huguenin, "Millivison Millimeter Wave Imagers," The National Institute of Justice, Office of Science and Technology Cooperative Agreement Project NO. 95-IJCX-KO07, Doc. No.181652, Washington DC, 2000. 